\title{
LA AMENAZA MULTIFORME DEL TERRORISMO
}

\author{
Gustavo Lagos Matus
}

\begin{abstract}
Si bien el fenómeno del terrorismo ha existido desde la antigüedad, desde los años sesenta ha emergido como un problema internacional significativo. Primeramente, en este estudio se distingue conceptualmente entre terrorismo y guerrilla, estrategias que a menudo se confunden. Luego se realiza una caracterización de los grupos terroristas, identificándose los tipos surgidos en Occidente en las décadas del 70 y 80 . Sin embargo, el autor señala que en la post-Guerra Fría los grupos fumandamentalistas islámicos manifiestan características particulares e identifica aquellos que se destacan por su fuerza y militancia. A pesar de que la sociedad ha debido enfrentar dificultades para defenderse de este fenómeno, debido a múltiples causas algunos movimientos surgidos en las décadas del 70 y 80 desaparecieron. iSucederá lo mismo con los grupos terroristas islámicos en los cuales intervienen factores religiosos fundamentalistas que estaban ausentes en las otras situaciones estudiadas?
\end{abstract}

El terrorismo es un fenómeno antiguo, pero emergió como un problema internacional significativo en los años 60 y creció hasta alcanzar proporciones epidémicas en los decenios del 70 y $80 .^{1}$

No siempre se ha hecho una clara distinción conceptual entre el terrorismo y la guerrilla. Existen numerosos casos en los cuales ambas estrategias utilizadas para debilitar y socavar el Estado se confunden o son aplicadas simultáneamente. El cientista político alemán Peter Waldmam ha propuesto distinguir analíticamente las diferencias entre ellas de acuerdo con el siguiente esquema:

\footnotetext{
${ }^{1}$ Charies W. Kegley Jr.y Eugene R. Wittkoph, World Politics. Trend and Transformation, (New York: St. Martins Press, 1993), 4' Edición, pp. 462-463.
} 
G. Lagos / La amenaza multiforme del terrorismo.

\section{FORMAS DE EMPLEO DE LA VIOLENCIA ORGANIZADA CONTRA EL ESTADO}

\begin{tabular}{|c|c|c|}
\hline & Terrorismo & Guerrilla \\
\hline $\begin{array}{l}\text { Función de la violen- } \\
\text { cia }\end{array}$ & $\begin{array}{l}\text { Principalmente simb6li- } \\
\text { co-comunicativa }\end{array}$ & $\begin{array}{l}\mathrm{La} \text { aplicación de la vio- } \\
\text { lencia sirve a fines ins- } \\
\text { trumentales }\end{array}$ \\
\hline Apoyo social & $\begin{array}{l}\text { Limitado a pequeños gru- } \\
\text { pos pertenecientes a la } \\
\text { clase media }\end{array}$ & $\begin{array}{l}\text { Incluye capas sociales } \\
\text { más amplias, en parti- } \\
\text { cular, de la población } \\
\text { rural }\end{array}$ \\
\hline Factor territorial & Sin base territorial & Con base territorial \\
\hline Dinámica & $\begin{array}{l}\text { Sin posibilidades de asu- } \\
\text { mir el poder político-mili- } \\
\text { tar; acción más bien con- } \\
\text { traproducente }\end{array}$ & $\begin{array}{l}\text { Con la posibilidad even- } \\
\text { tual de asumir el poder } \\
\text { político-militar }\end{array}$ \\
\hline
\end{tabular}

Fuente: Peter Waldman, "Terrorismo y Guerrilla: La violencia organizada contra el Estado en Europa y América Latina. Un análisis comparativo", Estudios Internacionales, No98, abril-junio 1992, p. 277.

En este análisis nos circunscribiremos al estudio del terrorismo.

La función simbólico-comunicativa consiste en que el acto violento representa un mensaje amenazador dirigido al entorno social de la víctima destinado a producir pánico induciendo formas de comportamiento dictadas por este sentimiento. "En el caso del terrorismo insurgente los agentes violentos esperan que los representantes del poder estatal, sobreestimando el peligro de insurrección proveniente de los terroristas, reaccionen de manera exagerada y sometan a la sociedad a una campaña de represión. Se espera que esta represión provoque indignación y resistencia en la población, de manera que en el curso de la escalada de la 'violencia de abajo' y de la 'violencia de arriba' se llegue finalmente a un levantamiento en masa y a la caída del gobierno atacado". ${ }^{2}$

Otra característica de los grupos terroristas es que ellos actúan sin base territorial ya que su estrategia consiste en estar presentes en todas partes y en ninguna al mismo tiempo; sus atentados se sitúan en lugares simbólicos destinados a afectar a todos y alcanzar así a

${ }^{2}$ Peter Waldman, op. cit, p. 278. 
todo el mundo con sus señales. Una tercera característica del terrorismo es que los movimientos de esta especie no tienen posibilidad de conquistar el poder político. No existe ningún caso en que un régimen atacado por los terroristas haya sido derrocado por un levantamiento en masa o haya caído bajo los excesos represivos der régimen atacado. Por lo general, los actos terroristas han provocado efectos contraproducentes en el sentido de que en lugar de socavar y quebrantar el régimen en cuestión, por el contrario han contribuido a consolidarlo.

En la siguiente tabla se ofrece una información resumida de diversos grupos terroristas en Occidente: 
G. Lagos / La amenaza multiforme del terrorismo.

\begin{tabular}{|c|c|c|c|c|}
\hline$\frac{E}{5}$ & 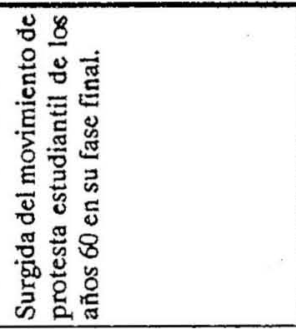 & 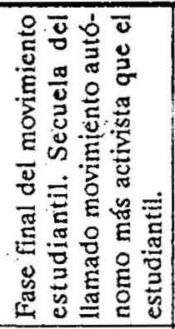 & 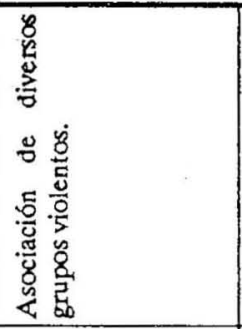 & 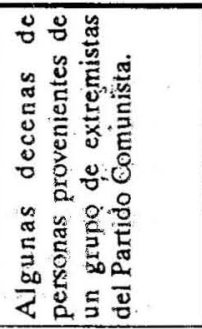 \\
\hline 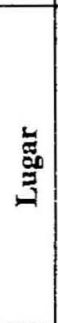 & 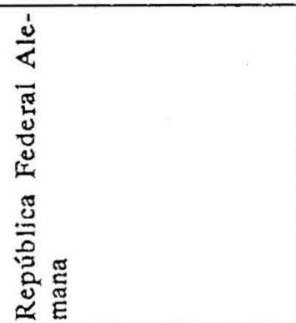 & $\stackrel{. \mathbb{3}}{\mathbb{g}}$ & 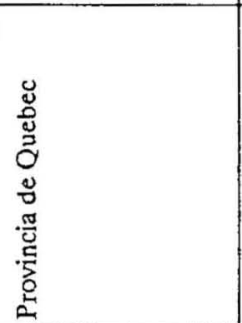 & 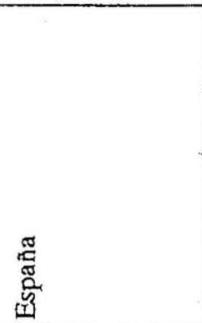 \\
\hline 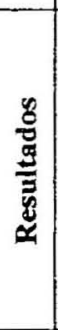 & 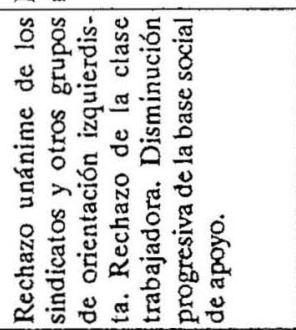 & 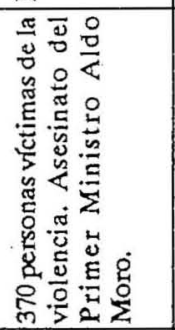 & 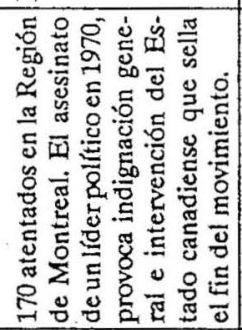 & 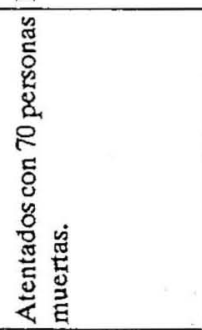 \\
\hline 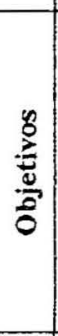 & 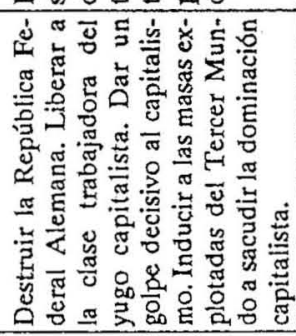 & 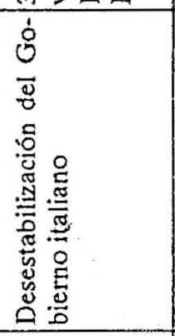 & 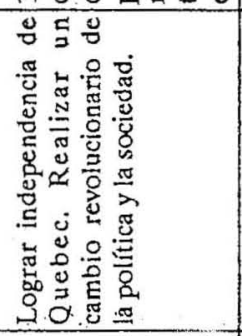 & 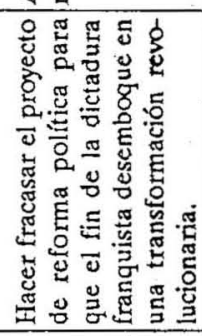 \\
\hline 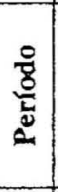 & 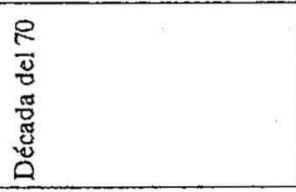 & 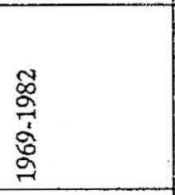 & 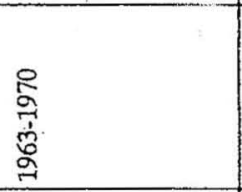 & 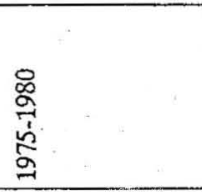 \\
\hline 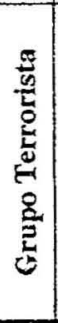 & 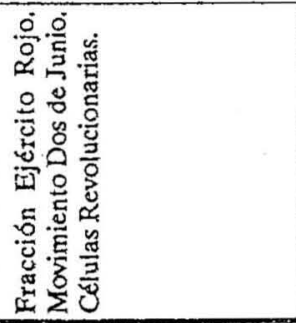 & 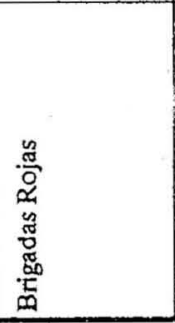 & 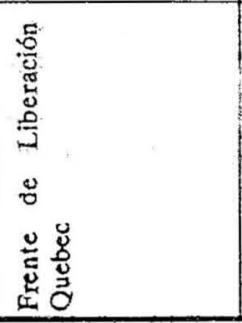 & 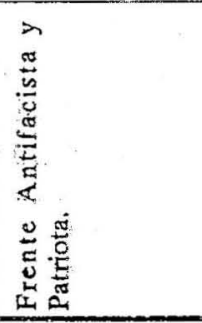 \\
\hline
\end{tabular}


Además de las formas típicas de terrorismo resumidas en la tabla anterior existen otras modalidades del terrorismo que reproducen parcialmente en el territorio europeo las tácticas de la técnica guerrillera. Nos referimos a la Eta Vasca y al Ira írlandés que constituyen casos de violencia étnica endémica. Ambos fueron iniciados por un puñado de intelectuales que tomaron la iniciativa de resistir y fundaron organizaciones adecuada a sus fines. Ambos perseguían la liberación de la mayoría opresora o del Estado centralista y se basaban en aspiraciones y movimientos nacionalistas que tenían sus raíces en el siglo XIX. "Por último, su resistencia era también comprensible para los espectadores en cuanto a que, efectivamente, tanto en España como Irlanda del Norte, los regímenes que ejercían el poder discriminaban sistemáticamente a las minorías étnicas o religiosas y las silenciaban políticamente" ${ }^{3}$ Por su carácter mismo de movimientos nacionalistas han dispuesto de un potencial de apoyo social mucho más amplio que las organizaciones terroristas típicas. Por otra parte el total de muertos causados por sus atentados ha sido muy superior al de las organizaciones terroristas típicas. Otra diferencia con dichas organizaciones es que ambos movimientos tienden a pensar en categorías espaciales, pues su meta final es conquistar un territorio determinado que debería transformarse en un estado soberano. La violencia étnica tiene para estos movimientos no sólo una función simbólica, sino, más que nada, el objetivo real de expulsar de la región al Estado central o bien a la mayoría considerados como potencias ocupantes.

Recientemente se ha originado un proceso de negociación entre el Ira irlandés, los movimientos protestantes y el Gobierno Británico en virtud del cual se ha declarado el cese del fuego por parte de las bandas armadas del Ira. Las milicias protestantes han cesado igualmente su lucha armada. Este proceso se encuentra aún en pleno desarrollo.

Con fecha 6 de septiembre de 1994, el partido Herri Bațasuna, brazo político de la organización independentista vasca Eta, ànunció que enviará una delegación a Irlanda del Norte para estudiar el proceso de paz que se está llevando a cabo en esa región después de que el Ejército Republicano Irlandés Ira anunció el alto del fuego. En un comunicado reciente, Herri Batasuna dio la noticia precisando

3 Ibid, p. 303.

4 ibid, p. 304. 
que el proceso de paz irlandés puede servir de ejemplo para España y el país Vasco. 5

En la post-Guerra Fría, el terrorismo ha adquirido características particulares porque la desaparición del conflicto Este-Oeste ha producido una laxitud en el sistema internacional, gracias a la cual ha surgido una proliferación de conflictos étnicos y regionales en los cuales se incuban nuevos movimientos radicales que conducen inevitablemente a formas inéditas de terrorismọ.

De acuerdo a un estudio realizado por un grupo de expertos hace un año en el Pentágono, el fenómeno de la globalización de la economía, correrá a parejas con un incremento global de la anarquía. Han aparecido términos como "terrorismo masivo", ejemplarizado por el que se está viviendo en Bosnia y Ruanda; $y$ "terrorismo aislado" como los actos recientemente producidos en Buenos Aires, Manhattan y Londres, efectuados por grupos radicales. Los análisis de los expertos del Pentágono llevaron a que Estados Unidos y sus aliados reforzaran los controles en sus fronteras y reconsideraran sus programas de recortar presupuesto y personal de sus unidades de contraterrorismo.

En el pasado, la CIA y las agencias extranjeras similares contribuyeron grandemente al desmantelamiento de grupos terroristas europeos como la Facción Ejército Rojo de Alemania y las Brigadas Rojas de Italia.

Según la opinión de un experto, "el contraterrorismo del futuro deberá prepararse para otró típo de tareas, como el de evitar la quiebra del sistema económico mediante la alteración de computadoras de los bancos" ${ }^{\prime \prime}{ }^{6}$

Con el colapso del comunismo, los planteamientos izquierdistas que inspiraron a "Carlos", "El Chacal"; y a otros subversivos han ido desapareciendo.

Actualmente las naciones occidentales temen atentados de fundamentalistas islámicos y la posibilidad de que grupos extremistas obtengan material nuclear de la ex-Unión Soviética.

Ahora el terrorismo está inspirado por motivos políticos y religiosos. La toma del poder en Irán por parte del Ayatola Khomeini hace 15 años, originó una ola fundamentalista cuyyas repercusiones en la actualidad se hacen sentir día a día.

${ }^{5}$ El Mercurio, 7 de septiembre de 1994.

${ }^{6}$ Kozo Ikeda, ¿Ofensiva del terror contra Occidente?, Visión 16, 31 de agosto, 1994, p. 13. 
En el mundo ahora hay cerca de 900 millones de musulmanes. Según la opinión de Emmanuel Sivan, quien fuera asesor del Primer Ministro de Israel hace diez años, el peligro no está en el islam en sí mismo sino en el movimiento revolucionario radicalizado, que se inspira en el islam y que incluye a cientos de organizaciones. Pero este movimiento es una minoría en el mundo islámico, aún cuando es una minoría muy activa. El problema es que este pequeño porcentaje se opone a la cultura occidental porque piensa que Occidente domina al mundo y es culpable en parte de la miseria de los países islámicos. Estos movimientos están interesados en luchar para la toma del poder en sus países a fin de reformarlos a su antojo. Como son minoría, están contra las elites dominantes dentro de sus países que son apoyadas por Occidente.

En la mayoría de los países islámicos estos grupos son minoritarios y están en la oposición. Sin embargo, en Irán y Sudán están ẹn el poder y por ello son más peligrosos porque tienen todos los recursos del Estado. Ellos creen que la doctrina islámica de lạ Guerra Santa, constituye la salvación.

Las crecientes sospechas de que el grupo terrorista islámico Hezbolá fue el autor del atentado contra la sede judía AMIA en Argentina y de que Irán le dio apoyo, está demostrando que las represalias contra Israel se están extendiendo a todo el mundo. El mismo origen tiene la colocación de bombas contra el edificio de la Segunda Avenida en Nueva York que alberga el Consulado General y la Misión de Israel y los atentados realizados en Londres contra sedes israelitas.

Esta oleada de terrorismo antiisraelí en vảrias capitales ha producido un alerta en Europa porque países como Alemania, Francia y los países nórdicos temen eventuales atentados contra las embajadas y organizaciones judías; por esta razón las autoridades de estos países han adoptado medidas de protección excepcionales para proteger los edificios israelíes.

Israel estima que Irán es el responsable de estos actos terroristas, aunque no cuente con pruebas fehacientes para ello.

Las razones de los grupos antiisraelíes para atacar a través del terrorismo son, según los observadores, el hecho de que la autonomía de Gaza y Jericó no derivó en el desmantelamiento de las 200 colonias judías que subsisten en los territorios ocupados, y que a pesar de los avanzados acuerdos de paz, Israel no dio un solo paso 
hacia atrás en ninguno de los territorios que ocupó a sus vecinos árabes después de la Guerra de los Seis Días (1967).

En ese contexto, el fin de estado de beligerancia y el acuerdo de paz entre Israel y Jordania alteraron aún más los ánimos en la oposición islámica, que considera al líder de la OLP, Yaser Arafat, un gran traidor de la causa Palestina.?

Arafat se encuentra en minoría en la dirección de la Organización para la Liberación de Palestina, y el Rey Husein de Jordania se debe enfrentar con la dura oposición de los "Hermanos Musulmanes" a la sazón partidarios del Hamas; ${ }^{8}$ a raíz del acuerdo de paz firmado entre Israel y Jordania, dicho enfrentamiento se ha agudizado.

Los distintos grupos terroristas que trabajan en su Guerra Santa por extender el islam se diferencian poco entre sí, ya sean egipcios, argelinos o libaneses. El financiamiento de estos grupos procede básicamente de Irán y Sudán (éste último con aspiraciones de ser una potencia islámica) por motivos ideológicos; de Siria, por intereses políticos en su conflicto con Israel; y también de simpatizantes radicalizados de los ricos países árabes.

Su estrategia se basa en la desestabilización del Estado, el acoso a los occidentales y al enemigo sionista de sus hermanos palestinos. Todos los grupos están en contacto, colaboran en su logística y, normalmente, cumplen con los intereses políticos de quienes los financian. En última instancia, su pretensión es provocar revoluciones populares que conviertan a sus países en Estados confesionales y proselitistas."

En el listado siguiente se puede observar a los grupos principales por su fuerza y militancia: ${ }^{10}$

HEZBOLLAH (Partido de Dios): Organización chí́ta libanesa nacida en 1982 y financiada por Irán, utilizada por Siria y cuyo objetivo principal es el acoso al vecino Israel.

YIHAD ISLAMICA: Su campo de actuación es Oriente Medio. Prácticamente trabaja según los intereses de Siria e Irán. Su relación con Hezbolláh es estrecha.

AMAL (Resistencia Islámica Libanesa): Hermanos de sangre de los dos anteriores.

${ }^{7}$ La Epoca, 28 de julio de 1994, p. 3.

I Ibid

9n Argelia se va al infiernon, Cambio 16, 22 de agosto de 1994.

${ }^{10}$ Fuente: Cambio 16, 22 de agosto de 1994, pp. $21-22$. 
HAMAS (Movimiento de Resistencia Islámico): Es la respuesta integrista palestina a la ocupación israelí de los territorios de Gaza y Cisjordania, surgida hace siete años con la Intifada. Es la oposición política-religiosa a la postura dialogante de la Organización para la Liberación de Palestina (OLP) liderada por Yaser Arafat.

GAMMA ISLAMIYA: Se conoce por este nombre al conjunto de organizaciones extremistas nacidas en Egipto. Están todas fuera de la ley. Sus facciones asesinaron al presidente Anuar el Sadat en el año 1981. Ahora su objetivo son los turistas occidentales para así cortar el flujo de divisas, imprescindible para el régimen, y provocar el colapso financiero:

HERMANOS MUSULMANES: Organización nacida en Egipto en el año 1982. Tiene una amplia influencia en los países de religión musulmana sunnita, como Jordania. Consideran la democracia conforme a sus creencias, pero quieren imponer la charia (ley islámica). EJERCITO ISLAMICO DE SAIVACION: Es el brazo armado del Frente Islámico de Salvación (FIS) argelino y comenzó a tomar cuerpo hace al menos un año. En él se intentan reunir las facciones fundamentalistas que combaten contra el régimen militar que les robó las elecciones. Con sus atentados -principalmente contra occidentalesquieren obligar al gobierno a retomar el proceso democrático que les otorgaba el poder.

GRUPO ISLAMICO ARMADO: La GLA está formada por los más extremistas y violentos de los radicales argelinos. Policía, ejército y occidentales son sus víctimas. Forman parte de él, ex combatientes de la guerra de Afganistán.

\section{¿Como puede una sociedad protegerse contra el terrorismo?}

A raíz de los atentados realizados en Nueva York, el jefe de la policía de esa ciudad tuvo una respuesta desalentadora: no parece haber una forma, dijo. En realidad esta respuesta parece ser realista considerando que el terrorismo de los grupos islámicos constituye verdaderamente una hidra de múltiples cabezas.

La comunidad internacional ha ensayado una serie de acciones cuya simple enumeración constituiría una larga lista y que no ban demostrado una gran eficacia. Una de las más importantes es la resolución 40-61 de la Asamblea General de las Naciones Unidas de 
diciembre de 1985 , que contiene las medidas para prevenir el terrorismo internacional que pone en peligro vidas humanas inocentes o causa su pérdida, compromete las libertades fundamentales, insta a estudiar las causas subyacentes de las formas de terrorismo y los actos de violencia que tienen su origen en las aflicciones, la frustración, los agravios y la desesperanza y que conducen a algunas personas a sacrificar vidas humanas, incluida la propia, en un intento de lograr cambios radicales. $^{11}$

No obstante estas apreciaciones negativas, cabe señalar que el estudio de los movimientos terroristas surgidos en Occidente en las décadas del 70 y del 80 en Alemania Federal, Italia, Quebec y España (resumidos en la tabla de este estudio inserta más arriba), revela que dichos movimientos desaparecieron con el tiempo. En Alemania Federal e Italia, se produjo una disminución progresiva de la base social de apoyo de los terroristas, junto con la acción de la CIA y agencias extranjeras similares. En Quebec, el movimiento desapareció también por causas semejantes. En España, por el fracaso del proyecto político terrorista (excluida ETA). Estas son experiencias que permiten pensar que el terrorismo, al cabo de cierto tiempo, debido a una serie de causas políticas y sociales, agota su capacidad de acción y termina por desaparecer.

¿Sucederá lo mismo con los grupos terroristas islámicos? Nadie podría dar una respuesta cierta a esta interrogante ya que en estos casos intervienen factores religiosos fundamentalistas cuyo comportamiento en el futuro sería imposible predecir.

\footnotetext{
${ }^{11}$ Pablo Antonio Fernández Sánchez, La obligación internacional de cooperar en la lucha contra el ttrorismo, (Madriđ, España: Ministerio đe Justicia, 1992), pp. 291-294.
} 